\title{
BMJ Open Relationship between education levels and booster counselling sessions on smoking cessation among Chinese smokers
}

\author{
Lei Wu, ${ }^{1,2}$ Yao He, ${ }^{1,2,3}$ Bin Jiang, ${ }^{4}$ Fang Zuo, ${ }^{4}$ Qinghui Liu, ${ }^{5}$ Li Zhang, ${ }^{6}$ \\ Changxi Zhou, ${ }^{5}$ Miao Liu, ${ }^{1,2}$ Hongyan Chen ${ }^{1,2}$
}

To cite: Wu L, He Y, Jiang $B$, et al. Relationship between education levels and booster counselling sessions on smoking cessation among Chinese smokers. BMJ Open 2015:5:e007885

doi:10.1136/bmjopen-2015007885

- Prepublication history and additional material is available. To view please visit the journal (http://dx.doi.org/ 10.1136/bmjopen-2015007885).

Received 9 February 2015

Revised 7 July 2015

Accepted 16 July 2015
CrossMark

For numbered affiliations see end of article.

Correspondence to Professor Yao He; yhe301@x263.net

\section{ABSTRACT}

Objectives: Although various effective interventions are available to help individuals quit smoking, the effect of educational levels on cessation rates has rarely been studied, and of the few intervention studies on this topic, the results have been conflicting.

Design and setting: From October 2008 to August 2013, a partly retrospective non-randomised study was conducted in a smoking cessation clinic of a large general hospital in Beijing, China.

Participants: In total, 547 Chinese smokers who sought treatment were divided into two groups: a face-toface counselling group ( $F C, n=149$ ) and an $F C$ group subjected to four telephone follow-up sessions (FCF, $\mathrm{n}=398$ ).

Outcomes: We evaluated self-reported cessation rates by day 7 and after 6 and 12 months and stratified the two groups by education levels.

Results: The 7-day and 6-month and 12-month continuous cessation rates of smokers of low education levels in the FC group at the time of the 12-month followup were $12.5 \%, 7.1 \%$ and $7.1 \%$, respectively, which were lower than those of the highly educated smokers $(16.1 \%, 12.9 \%$ and $9.7 \%$, respectively). The results were opposite for the FCF group. The corresponding results for the highly educated smokers of the FCF group were $25.0 \%, 17.2 \%$ and $10.3 \%$, respectively, which were lower than those for the smokers of low education levels (28.3\%, $22.9 \%$ and $18.1 \%$, respectively). However, significant differences were observed only among the FCF group participants who had experienced 12 months of continuous abstinence, and the crude $\mathrm{OR}$ for these individuals was recorded at 0.52 ( 0.29 to 0.93 ), $p=0.03$. A stepwise logistic regression showed that education levels may play a role in various intervention methods. Being married and higher Fagerström test scores were also predictors of cessation tendencies.

Conclusions: Education levels may affect the benefits of booster counselling sessions on smoking cessation among Chinese smokers.

\section{INTRODUCTION}

Tobacco consumption constitutes a major global public health challenge, especially in

\section{Strengths and limitations of this study}

- This partly retrospective non-randomised study evaluated the effect of 'booster' counselling sessions provided in combination with brief face-to-face counselling sessions with Chinese patients visiting a smoking cessation clinic.

- The present study shows that education levels have varying effects on various types of behavioural supports; smokers with lower levels of education benefited more from the boosters.

- Further trials comparing various levels of behavioural support should report outcomes stratified by educational levels.

- Although the data were collected systematically in a smoking cessation clinic, the study is limited by its small sample size.

- The findings are largely based on self-reports; thus, socially desirable responses may have been given.

China. According to the Global Adult Survey conducted in 2010, smoking prevalence in China was recorded at $52.9 \%$ among men and $2.4 \%$ among women. ${ }^{12}$ In China, where smoking cessation and cessation services are in their infancy, smoking cessation services are scarce and of limited effectiveness. Although they have been proven effective in clinical practices in Mainland China, ${ }^{3}$ smoking cessation medications are too expensive to be used widely among Chinese smokers, especially among low-income smokers. Therefore, cost-effective ways of increasing cessation success rates in China are urgently needed.

Previous results of cross-sectional and population-based surveys have shown that smokers with higher levels of education or who occupy higher social positions are more likely to intend or attempt to quit or to refrain from smoking. ${ }^{4-6}$ Although there are various effective interventions that help 
individuals quit smoking, ${ }^{7-10}$ the effect of educational levels on cessation rates has seldom been studied, and the results of the few intervention studies that have been conducted are conflicting. Some of these studies have reported that higher education levels are associated with higher cessation rates. ${ }^{11-13}$ However, one study found the opposite result, ${ }^{14}$ and other studies have found no relationship between education levels and cessation rates. ${ }^{15} 16$ Although the results were not significant, two Chinese studies have implied that smokers with low levels of education are more likely to quit smoking in Mainland China. ${ }^{17}{ }^{18}$ Most intervention studies have not reported on the frequency and intensity of counselling sessions or did not use a control group.

Given the conflicting results of previous studies, we hypothesise that educational levels may play various roles in various types of behavioural supports (different counselling frequencies and intensities). This study evaluates the impact of education levels on various intervention groups. We compare the effect of one session of face-to-face individual counselling in combination with four follow-up telephone counselling sessions (FCF) with that of face-to-face counselling alone (FC); both groups are stratified by education level. We apply a smoking cessation intervention of standard intensity levels in one of the longest running Smoking Cessation Clinics (SCG) in Mainland China.

\section{METHODS}

The investigation involved an observational study based on a retrospective analysis of data collected systematically in an SCC. We established an SCC in the outpatient department of the People's Liberation Army General Hospital in Beijing, which is one of the largest hospitals in China. The SCC began operations on 22 October 2008 and still exists. Trained physicians provide services similar to those offered in Hong Kong on 4-weekday evenings (Monday to Thursday, from 18:30 to 21:00). ${ }^{19}$ The participants were smokers who voluntarily sought treatment from our SCC and paid a $¥ 7$ (US\$1) registration fee.

Before the baseline treatment was offered, each clinic attendee was asked to sign an informed consent form. Information on the project objectives (their data were used only for scientific research), assessments and data collection methods was reported on a paper form. Each participant was also asked for a telephone number that he or she could be reached at for the follow-up interviews.

\section{Inclusion and exclusion criteria}

Study subjects were required to satisfy the following inclusion criteria: (1) current smokers (who smoked daily for at least 6 months at the time of the survey), ${ }^{20}$ Chinese, 18 years of age or older, and (2) consent to participate in the follow-up sessions and completion of an informed consent form. Subjects who were cognitively impaired (deaf, could not understand and complete the questionnaire reliably, etc.) were excluded from the study.

\section{Subject recruitment and intervention}

The FC group and FCF group included smokers who voluntarily sought treatment from our SCC in the PLA general hospital. Each smoker received the same intervention treatment at the time of his or her first visit, and no smoking cessation medications were provided. The participants' smoking and related information was assessed using a baseline questionnaire in a face-to-face interview that lasted approximately $10 \mathrm{~min}$ prior to counselling. The physician then provided individual FC based on Prochaska's transtheoretical model ${ }^{21}$ and on the 'five A's' (ask, advise, assess, assist and arrange), lasting at least $30 \mathrm{~min}$. The physician assessed each client's readiness to quit smoking, strengthened each client's motivation to quit smoking using the 'five R's' (relevance, risks, rewards, roadblocks and repetition), ${ }^{22}$ and provided advice on ways of overcoming psychological cravings, psychological dependence and sociocultural factors associated with tobacco dependency. ${ }^{19}$

After the baseline intervention, smokers who visited our clinic from October of 2008 to December of 2010 $(n=254)$ participated in follow-up telephone conversations with counsellors after the first week and after one, three, 6 and 12 months. At the first week and first, third and sixth month follow-up meetings, after each client's smoking or cessation status was assessed, we conducted a 'booster' session and asked whether the smokers or quitters had experienced any problems, offered problem-oriented suggestions or advice when necessary, and encouraged the clients to quit or to continue abstaining from smoking. Each follow-up lasted approximately $15-20 \mathrm{~min}$.

In studying the effect of the follow-up booster session, we could not perform a randomised controlled trial (RCT) under clinical conditions as randomly allocating the smokers to two groups with different follow-up interventions would have confused the smokers as they sought a service and did not expect to be randomised. Given the uncertainties regarding whether the follow-up booster was effective, we ceased booster counselling for all of the smokers first counselled in 2011. These smokers were given the same telephone follow-up assessment by trained counsellors after the first, third and sixth months that strictly involved conversations about smoking and quitting and that involved no further counselling. Each follow-up session lasted approximately 2-3 min. These smokers constituted the FC group (FC, $\mathrm{n}=149)$.

After 2011, we resumed the follow-up booster counselling sessions for all of the smokers. Those participating from February of 2012 to August of 2013 ( $\mathrm{n}=144)$ and those participating from October of 2008 to December of 2010 formed the FC plus FCF group (total $n=398$ ). 
We completed 12 months of follow-up sessions with all of the smokers in August of 2014.

All participating physicians and counsellors completed a smoking cessation training programme and passed the required examinations. To guarantee the integrity and quality of the counselling services, the counsellors were supervised throughout the project. The counsellors were instructed to contact the smokers of the two groups at least seven times on different days before removing them from the follow-up group. The physicians who provided baseline counselling were unaware of the grouping methods. Although the counsellors who administered the follow-up booster sessions could not be blinded to the participants and their objectives during the booster sessions, they were not informed of the aims of the research and thus recorded tobacco use status levels with minimal subjective bias.

\section{Data collection}

Data collection was performed during the first visit and at each follow-up interview with the use of standardised and structured questionnaires. The questionnaires were developed on the basis of those widely used in Hong Kong. ${ }^{19} 23$ The following baseline demographic data were collected for each patient: age, marital status, occupation and monthly family income. Education levels were categorised as low (high school and below, including primary, intermediate and high school degrees; 0-12 years of formal schooling) and high (college and above, including tertiary education, higher vocational school degrees, and college or university degrees; more than 12 years of formal schooling). ${ }^{17}$ Tobacco-related questions focused on each client's readiness to quit smoking (precontemplation, contemplation, preparation and action); smoking history; smoking status; smoking destinations; cessation history; cessation motivations; and perceived confidence, importance and difficulties associated with smoking cessation (all three were based on a scale of 1-100, from the least to the most). All smokers were submitted to the Fagerström Test for Nicotine Dependence (FTND), and their dependence was classified as low (0-3), moderate (4-5) or severe (6-10). ${ }^{21}$ Exhaled carbon monoxide levels were measured by trained technicians following a standard protocol and a Micro CO Smokerlizer. ${ }^{23}$ Additional questions focused on previous medical advice given on smoking cessation, on physician diagnoses of tobacco-related chronic diseases and on alcohol use. The follow-up questionnaires were similar to the baseline questionnaires, with the omission of redundant questions and the addition of questions on cessation times, cessation attempts and withdrawal symptoms.

\section{Statistical analysis}

The data were entered (double entry) using Epidata (3.1) and were analysed using SPSS (Inc., Chicago, Illinois, USA) for Windows (19.0). The baseline characteristics were described via descriptive statistics.
Cessation prevalence according to the baseline factors was compared with the $\chi^{2}$ test results. We employed forward stepwise logistic regressions to identify independent predictors of cessation success and to calculate adjusted OR and 95\% CIs. Following intention to treat (ITT) analysis principles, smokers who could not be contacted during the follow-up period were considered nonquitters or non-reducers. A per protocol (PP) analysis was performed by excluding those who did not participate in the follow-up sessions as part of a sensitivity analysis. All of the $p$ values were two sided, and $p<0.05$ was employed as the level of statistical significance.

The 7-day cessation condition was defined as smoking cessation for the past 7 days at the time of the 12-month follow-up following the USA Clinical Practice Guidelines. ${ }^{22}$ Six-month and 12-month continuous cessation rates were defined as smoking cessation over the past 6 or 12 months, respectively, at the time of the 12-month follow-up session. All of these results were selfreported by the smokers, and some of them were confirmed via biochemical validation.

\section{RESULTS}

From 22 October 2008 to 31 August 2013, 547 eligible smokers were seen. By 31 August 2014, 407 smokers had completed the 12-month follow-up process, and 140 smokers $(18.8 \%$ in FC, $28.1 \%$ in FCF, and $25.6 \%$ in total) did not participate in the follow-up session, primarily due to lack of contact (figure 1). These 140 individuals shared similar baseline demographic features and other characteristics with the 407 clients who completed the 12-month follow-up process (see online supplementary appendix table $\mathrm{S} 1$ ).

\section{Demographic and tobacco-related characteristics and other factors}

This study examined 547 smokers, and the mean age of the smokers was 41.0 years, with an SD of 11.1. Most of the smokers were married $(87.6 \%)$, currently employed $(79.7 \%)$, smoked more than 20 cigarettes per day $(61.6 \%)$ and had made prior cessation attempts $(75.3 \%)$.

After we stratified each group into two education levels, the four groups were similar in most of the factors (table 1). Compared to well-educated smokers, smokers with a low level of education had lower incomes, were more likely to be unemployed, presented longer smoking histories and exhibited stronger intentions to quit smoking.

\section{Cessation rates}

Overall, the 7-day and 6-month and 12-month continuous cessation rates of the $\mathrm{FC}$ group were recorded at $14.8 \%, 10.7 \%$ and $8.7 \%$, respectively, which were lower than those of the FCF group (26.4\%, 19.6\% and 13.6\%, respectively). Table 2 shows that according to the ITT analysis, at the time of the 12-month follow-up, the 7-day and 6-month and 12-month continuous cessation rates 


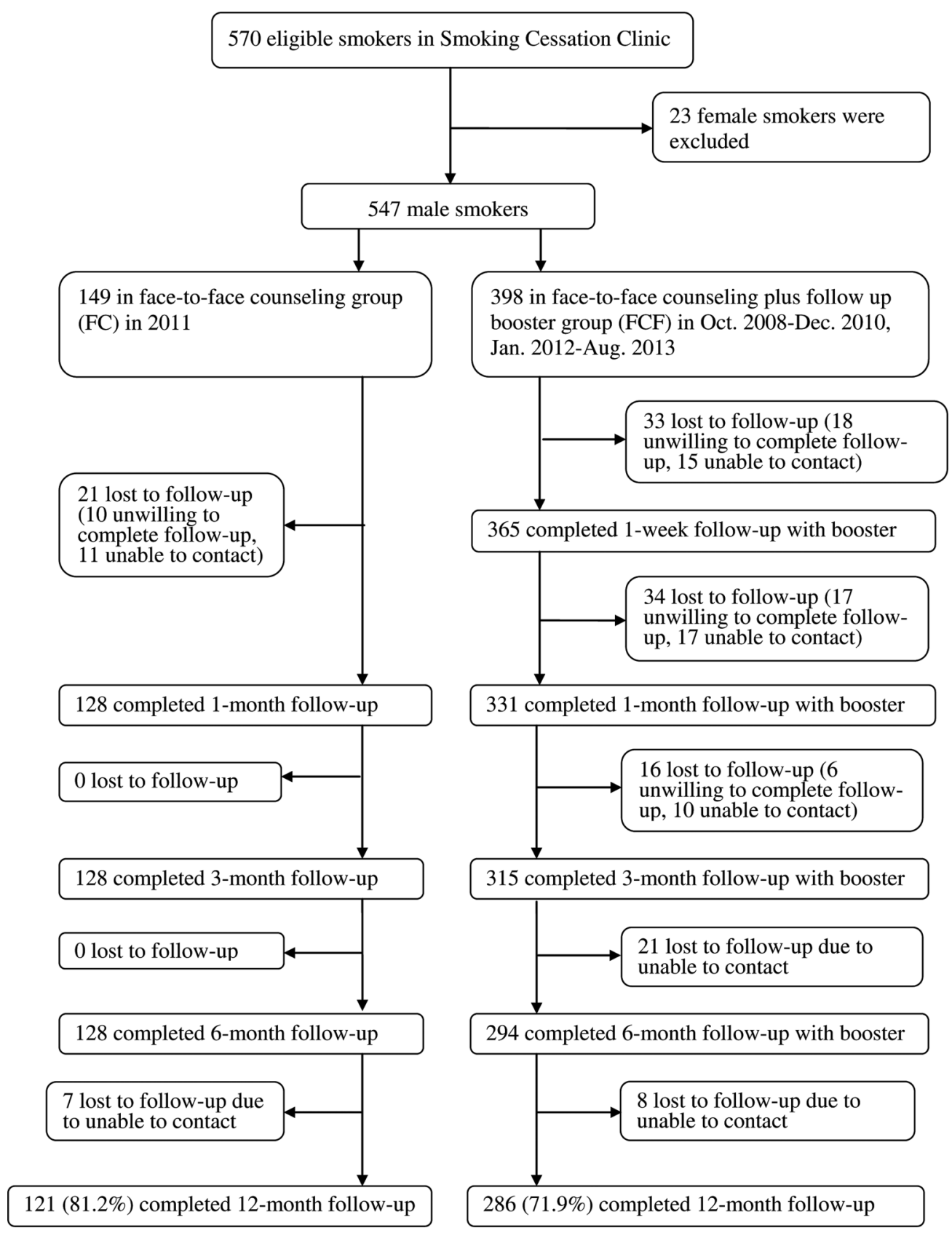

Figure 1 Attrition flow chart.

of the low education level smokers in the FC group were recorded at $12.5 \%, 7.1 \%$ and $7.1 \%$, respectively, which were lower than those of the highly educated smokers $(16.1 \%, 12.9 \%$ and $9.7 \%$, respectively). However, inverse results were found for the FCF group. The 7-day and 6-month and 12-month continuous cessation rates of the highly educated smokers in the FCF group were recorded at $25.0 \%, 17.2 \%$ and $10.3 \%$, respectively, which were lower than those of smokers with low levels of education $(28.3 \%, 22.9 \%$ and $18.1 \%$, respectively). However, only the 12-month continuous abstinence cessation rate of the FCF group showed a significant difference across educational levels (crude OR, 0.52; 95\% CI 0.29 to 0.93 ; $\mathrm{p}=0.03$ ). After adjusting for confounding variables, the difference was found to be marginally significant (adjusted OR, 0.59; 95\% CI 0.29 to $1.21 ; \mathrm{p}=0.15$ ).

The PP analysis generated similar results, as shown in online supplementary appendix table S2. The 12-month continuous abstinence cessation rate of the highly educated smokers in the FCF group was significantly lower than that of the smokers with low levels of education, and the crude OR $(95 \% \mathrm{CI})$ was recorded at $0.45(0.25$ to $0.81)$. The difference in the 6 -month continuous abstinence cessation rate was marginally significant, and the crude OR ( $95 \%$ CI) was found to be 0.59 (0.35 to 1.01).

As shown in online supplementary appendix table S3, according to the ITT and complete case (PP) analyses, outcome patterns were similar for both FCF periods 
Table 1 Demographic characteristics, tobacco related and other factors of 547 smokers in two groups of different education levels

\begin{tabular}{|c|c|c|c|c|c|c|}
\hline \multirow[b]{2}{*}{$\begin{array}{l}\text { Demographic } \\
\text { characteristics }\end{array}$} & \multirow[b]{2}{*}{$\begin{array}{l}\text { Total } \\
(\mathrm{N}=547)\end{array}$} & \multicolumn{2}{|l|}{ FC (N=149) } & \multicolumn{2}{|l|}{ FCF $(\mathrm{N}=398)$} & \multirow[b]{2}{*}{ p Value } \\
\hline & & $\begin{array}{l}\text { Low education } \\
\text { level }(\mathrm{N}=56)\end{array}$ & $\begin{array}{l}\text { High education } \\
\text { level }(\mathrm{N}=93)\end{array}$ & $\begin{array}{l}\text { Low education } \\
\text { level }(\mathrm{N}=166)\end{array}$ & $\begin{array}{l}\text { High education } \\
\text { level }(\mathrm{N}=232)\end{array}$ & \\
\hline Age (years), Mean (SD) & $41.0(11.1)$ & $42.1(11.5)$ & $40.5(9.2)$ & $42.0(12.7)$ & $40.2(10.5)$ & 0.34 \\
\hline \multicolumn{7}{|l|}{ Age (years) number, $\mathrm{N}(\%)$} \\
\hline$<31$ & $100(18.3)$ & $9(16.1)$ & $13(14.0)$ & $30(18.1)$ & $48(20.7)$ & 0.15 \\
\hline $31-40$ & $174(31.8)$ & $16(28.6)$ & $32(34.4)$ & $48(28.9)$ & 78 (33.6) & \\
\hline $41-50$ & $168(30.7)$ & $18(32.1)$ & $36(38.7)$ & $45(27.1)$ & $69(29.7)$ & \\
\hline$>50$ & $105(19.2)$ & $13(23.2)$ & $12(12.9)$ & $43(25.9)$ & 37 (15.9) & \\
\hline \multicolumn{7}{|l|}{ Marital status } \\
\hline Married & $479(87.6)$ & $51(91.1)$ & $83(89.2)$ & $144(86.7)$ & $201(86.6)$ & 0.76 \\
\hline Single or divorced & 68 (12.4) & $5(8.9)$ & $10(10.8)$ & $22(13.3)$ & $31(13.4)$ & \\
\hline \multicolumn{7}{|l|}{ Occupation (\%) } \\
\hline Currently employed & 436 (79.7) & 37 (66.1) & $81(87.1)$ & $100(60.2)$ & 218 (94.0) & $<0.001$ \\
\hline $\begin{array}{l}\text { Student/unemployed/ } \\
\text { retired/others }\end{array}$ & $111(20.3)$ & $19(33.9)$ & $12(12.9)$ & $66(39.8)$ & $14(6.0)$ & \\
\hline \multicolumn{7}{|c|}{ Family income per month ( $¥$, US\$1= $¥ 6$ ) } \\
\hline$<3000$ & $203(37.1)$ & $37(66.1)$ & $21(22.6)$ & $91(54.8)$ & $54(23.3)$ & $<0.001$ \\
\hline $3000 \sim 6000$ & $150(27.4)$ & $7(12.5)$ & $30(32.3)$ & $38(22.9)$ & 75 (32.3) & \\
\hline$>6000$ & $194(35.5)$ & $12(21.4)$ & $42(45.2)$ & $37(22.3)$ & $103(44.4)$ & \\
\hline \multicolumn{7}{|c|}{ Tobacco-related factors } \\
\hline \multicolumn{7}{|c|}{ Cigarettes smoked on average daily (cigarette/day) } \\
\hline$\geq 20$ & $337(61.6)$ & $37(66.1)$ & $59(63.4)$ & $104(62.7)$ & $137(59.1)$ & 0.60 \\
\hline $10-19$ & $157(28.7)$ & $13(23.2)$ & $27(29.0)$ & $42(25.3)$ & 75 (32.3) & \\
\hline$<10$ & $53(9.7)$ & $6(10.7)$ & $7(7.5)$ & $20(12.0)$ & $20(8.6)$ & \\
\hline \multicolumn{7}{|l|}{ Smoking duration (years) } \\
\hline$<20$ & $234(42.8)$ & $18(32.1)$ & $41(44.1)$ & $61(36.7)$ & $114(49.1)$ & 0.03 \\
\hline$\geq 20$ & $313(57.2)$ & 38 (67.9) & $52(55.9)$ & 105 (63.3) & $118(50.9)$ & \\
\hline \multicolumn{7}{|c|}{ Prior attempts to quit smoking } \\
\hline 0 & $135(24.7)$ & $10(17.9)$ & $23(24.7)$ & $44(26.5)$ & $58(25.0)$ & 0.63 \\
\hline$\geq 1$ & $412(75.3)$ & $46(82.1)$ & $70(75.3)$ & $122(73.5)$ & $174(75.0)$ & \\
\hline \multicolumn{7}{|l|}{ Fagerström test score } \\
\hline Severe $(6-10)$ & $246(45.0)$ & $30(53.6)$ & $35(37.6)$ & $83(50.0)$ & $98(42.2)$ & 0.26 \\
\hline Moderate (4-5) & $133(24.3)$ & $13(23.2)$ & $29(31.2)$ & $35(21.1)$ & $56(24.1)$ & \\
\hline $\operatorname{Low}(0-3)$ & $168(30.7)$ & $13(23.2)$ & $29(31.2)$ & $48(28.9)$ & 78 (33.6) & \\
\hline \multicolumn{7}{|l|}{ Stage of quitting smoking } \\
\hline $\begin{array}{l}\text { Contemplation/ } \\
\text { precontemplation }\end{array}$ & $134(24.5)$ & $10(17.9)$ & $33(35.5)$ & 37 (22.3) & $54(23.3)$ & 0.03 \\
\hline Preparation & $197(36.0)$ & $16(28.6)$ & $35(37.6)$ & $58(34.9)$ & $88(37.9)$ & \\
\hline Action & $216(39.5)$ & $30(53.6)$ & $25(26.9)$ & $71(42.8)$ & $90(38.8)$ & \\
\hline \multicolumn{7}{|c|}{ Perceived health status at the first visit } \\
\hline Fair/bad/very bad & $363(66.4)$ & $38(67.9)$ & $55(59.1)$ & $113(68.1)$ & $157(67.7)$ & 0.45 \\
\hline Very good/good & $184(33.6)$ & $18(32.1)$ & $38(40.9)$ & 53 (31.9) & 75 (32.3) & \\
\hline \multicolumn{7}{|c|}{ Expenditure on cigarettes per day, $¥$} \\
\hline$<20$ & $261(47.7)$ & $31(55.4)$ & $45(48.4)$ & $79(47.6)$ & $106(45.7)$ & 0.64 \\
\hline$\geq 20$ & 286 (52.3) & $25(44.6)$ & $48(51.6)$ & $87(52.4)$ & $126(54.3)$ & \\
\hline Medical advice to quit & $187(34.2)$ & $19(33.9)$ & $29(31.2)$ & 53 (31.9) & $86(37.1)$ & 0.66 \\
\hline $\begin{array}{l}\text { Had doctor diagnosed } \\
\text { tobacco related diseases }\end{array}$ & $290(53.0)$ & $28(50.0)$ & $47(50.5)$ & 95 (57.2) & $120(51.7)$ & 0.62 \\
\hline Current drinkers & $380(69.5)$ & $34(60.7)$ & $72(77.4)$ & $116(69.9)$ & $158(68.1)$ & 0.17 \\
\hline $\begin{array}{l}\text { Exhaled CO level at first } \\
\text { visit, Mean (SD) }\end{array}$ & $11.8(7.8)$ & $10.8(6.5)$ & $12.5(7.6)$ & $11.0(7.7)$ & $12.3(8.1)$ & 0.23 \\
\hline $\begin{array}{l}\text { Perceived importance of } \\
\text { quitting, Mean (SD) }\end{array}$ & $85.8(17.3)$ & $86.5(15.6)$ & $85.9(16.2)$ & $86.3(18.0)$ & $85.3(17.6)$ & 0.94 \\
\hline $\begin{array}{l}\text { Perceived difficulty in } \\
\text { quitting, Mean (SD) }\end{array}$ & $72.6(23.2)$ & $78.8(18.5)$ & $77.4(21.3)$ & $69.6(24.7)$ & $71.4(23.5)$ & 0.01 \\
\hline $\begin{array}{l}\text { Perceived confidence in } \\
\text { quitting, Mean (SD) }\end{array}$ & $67.6(23.9)$ & $73.6(22.5)$ & $66.4(22.0)$ & $69.9(25.2)$ & $65.0(23.7)$ & 0.05 \\
\hline
\end{tabular}


Table 2 Quit rates of two groups at 12-month follow-up in 547 smokers by intention to treat N (\%)

\begin{tabular}{|c|c|c|c|c|c|c|}
\hline & $\begin{array}{l}\text { Low } \\
\text { education } \\
\text { level }\end{array}$ & $\begin{array}{l}\text { High } \\
\text { education } \\
\text { level }\end{array}$ & $\begin{array}{l}\text { Crude OR } \\
(95 \% \mathrm{Cl})\end{array}$ & p Value & $\begin{array}{l}\text { Adjusted OR* } \\
(95 \% \mathrm{Cl})\end{array}$ & p Value \\
\hline FC & $(\mathrm{N}=56)$ & $(\mathrm{N}=93)$ & & & & \\
\hline \multicolumn{7}{|l|}{ 12-month follow-up } \\
\hline 7-day point prevalence & $7(12.5)$ & $15(16.1)$ & 1.35 (0.51 to 3.54$)$ & 0.55 & $1.31(0.37$ to 4.71$)$ & 0.68 \\
\hline $\begin{array}{l}\text { 6-month continuous } \\
\text { abstinence }\end{array}$ & $4(7.1)$ & $12(12.9)$ & 1.93 (0.59 to 6.29$)$ & 0.28 & 2.85 (0.62 to 13.06$)$ & 0.18 \\
\hline $\begin{array}{l}\text { 12-month continuous } \\
\text { abstinence }\end{array}$ & $4(7.1)$ & $9(9.7)$ & $1.39(0.41$ to 4.75$)$ & 0.60 & 2.02 (0.41 to 9.95$)$ & 0.39 \\
\hline FCF & $(\mathrm{N}=166)$ & $(\mathrm{N}=232)$ & & & & \\
\hline \multicolumn{7}{|l|}{ 12-month follow-up } \\
\hline 7-day point prevalence & $47(28.3)$ & $58(25.0)$ & 0.84 (0.54 to 1.32$)$ & 0.46 & 0.90 (0.52 to 1.56$)$ & 0.70 \\
\hline $\begin{array}{l}\text { 6-month continuous } \\
\text { abstinence }\end{array}$ & $38(22.9)$ & $40(17.2)$ & $0.70(0.43$ to 1.15$)$ & 0.16 & 0.79 (0.43 to 1.45$)$ & 0.44 \\
\hline $\begin{array}{l}\text { 12-month continuous } \\
\text { abstinence }\end{array}$ & $30(18.1)$ & $24(10.3)$ & 0.52 (0.29 to 0.93$)$ & 0.03 & 0.59 (0.29 to 1.21$)$ & 0.15 \\
\hline
\end{tabular}

(from October of 2008 to December of 2010 and from January of 2012 to August of 2013), suggesting an absence of period effects.

\section{Predictors of cessation}

To diminish the confounding property of population differences, all factors were entered into the stepwise logistic model, with the exception of cigarette consumption (as cigarette consumption was a major item of the Fagerström test). According to the ITT analysis shown in table 3, low education levels in the FCF group and Fagerström test scores were strong predictors of smoking cessation at the time of the 12-month follow-up meeting for all cessation rates (7-day and 6-month and 12-month continuous cessation rates). Marital status was also a significant independent predictor of 6-month and 12-month continuous cessation rates.

The analysis of the 12-month continuous cessation rate showed that compared to smokers with low levels of education in the FC group, the ORs (95\% CI) of highly educated smokers in the FC and FCF groups and of low education level smokers in the FCF group were 1.20 (0.34 to 4.16$), 1.40$ (0.46 to 4.28$)$ and 3.06 (1.01 to $9.30)$, respectively. The Fagerström test score exhibited a negative dose-response relationship, wherein the ORs (95\% CI) of the Fagerström scores of 4-5 and 0-3 were 3.34 (1.63 to 6.84 ) and 3.89 (2.00 to 7.57), respectively.

The cessation predictor results were almost identical according to the PP analysis (see online supplementary appendix table $\mathrm{S} 4)$.

\section{DISCUSSION}

Our SCC is one of the oldest part-time SCC in Mainland China for which research evidence on intervention effectiveness is scarce. Using systematically collected data, we evaluated the effectiveness of offering one FC session $(40 \mathrm{~min})$ in combination with four brief follow-up telephone counselling sessions (15-20 min each) in relation to the effectiveness of FC alone; we stratified the participant groups by education level. Our study generated new evidence of the impact of education levels on various intervention methods directed at Chinese male smokers. Although our study was not designed as an RCT, the results were most likely not affected by extraneous factors and may prove applicable to 'real world' contexts.

Sociodemographic factors may have impacted the smoking cessation tendencies of the smokers voluntarily participating in our clinic more relative to the general population. The smokers who participated in our SCC were largely middle-aged, which is consistent with China's national census, which shows that the working population of 40-49 years of age exhibits the highest degree of smoking prevalence. ${ }^{2}$ Most smokers in our SCC exhibited higher levels of tobacco consumption and generated higher Fagerström scores than smokers in Hong Kong and Guangzhou and those represented in western SCC reports. ${ }^{17} 23-25$

In accordance with the results of previous reports, ${ }^{25-27}$ the telephone follow-up sessions significantly increased cessation rates. In this study, we found that the telephone follow-up sessions significantly increased both the 7-day and 6-month continuous cessation rates at the time of the 12-month follow-up sessions (the 12-month continuous cessation rate was marginally significant). However, after each group was stratified by education level, the results showed that education levels may play various roles in various intervention methods. In the FC group, the highly educated smokers were more likely to quit; and an inverse relationship was found in the FCF group. This study confirms previous research that shows 
Table 3 By intention to treat, logistic regression (stepwise) analysis for adjusted OR for predictors of quitting at 12-month follow-up

\begin{tabular}{|c|c|c|c|}
\hline Predictors & Adjusted OR* $(95 \% \mathrm{Cl})$ & p Value & $p$ for trend \\
\hline \multicolumn{4}{|l|}{ 7-day point prevalence } \\
\hline \multicolumn{4}{|l|}{ Group } \\
\hline FC+low education Level & 1.00 & & \multirow[t]{4}{*}{0.03} \\
\hline FC+high education Level & $1.19(0.45$ to 3.17$)$ & 0.73 & \\
\hline FCF+high Education level & 2.12 (9.00 to 5.00$)$ & 0.09 & \\
\hline FCF+low education Level & 2.71 (1.13 to 6.50$)$ & 0.03 & \\
\hline \multicolumn{4}{|l|}{ Fagerström test score } \\
\hline Severe $(6-10)$ & 1.00 & & \multirow[t]{3}{*}{$<0.001$} \\
\hline Moderate (4-5) & 1.75 (1.03 to 3.00$)$ & 0.04 & \\
\hline Low (0-3) & 2.95 (1.83 to 4.74$)$ & $<0.001$ & \\
\hline \multicolumn{4}{|l|}{ 6-month continuous abstinence } \\
\hline \multicolumn{4}{|l|}{ Group } \\
\hline FC+low education level & 1.00 & & \multirow[t]{4}{*}{0.02} \\
\hline FC+high education level & 1.73 (0.52 to 5.74$)$ & 0.37 & \\
\hline FCF+high education level & 2.59 (0.88 to 7.67$)$ & 0.09 & \\
\hline FCF+low education level & 4.04 (1.35 to 12.04$)$ & 0.01 & \\
\hline \multicolumn{4}{|l|}{ Marital status } \\
\hline Single or divorced & 1.00 & & \\
\hline Married & 2.71 (1.12 to 6.57$)$ & 0.03 & \\
\hline \multicolumn{4}{|l|}{ Fagerström test } \\
\hline Severe $(6-10)$ & 1.00 & & \multirow[t]{3}{*}{0.001} \\
\hline Moderate (4-5) & 2.08 (1.14 to 3.80$)$ & 0.02 & \\
\hline Low (0-3) & 2.89 (1.68 to 4.97$)$ & $<0.001$ & \\
\hline \multicolumn{4}{|c|}{ 12-month continuous abstinence } \\
\hline \multicolumn{4}{|l|}{ Group } \\
\hline FC+low education level & 1.00 & & \multirow[t]{4}{*}{0.02} \\
\hline FC+high education level & 1.20 (0.34 to 4.16$)$ & 0.78 & \\
\hline FCF+high education level & 1.40 (0.46 to 4.28$)$ & 0.56 & \\
\hline FCF+low education level & 3.06 (1.01 to 9.30$)$ & 0.05 & \\
\hline \multicolumn{4}{|l|}{ Marital status } \\
\hline Single or divorced & 1.00 & & \\
\hline Married & $4.02(1.21$ to 13.41$)$ & 0.02 & \\
\hline \multicolumn{4}{|l|}{ Fagerström test } \\
\hline Severe $(6-10)$ & 1.00 & & \multirow[t]{3}{*}{$<0.001$} \\
\hline Moderate (4-5) & 3.34 (1.63 to 6.84$)$ & 0.001 & \\
\hline Low $(0-3)$ & 3.89 (2.00 to 7.57$)$ & $<0.001$ & \\
\hline
\end{tabular}

that low SES groups are more likely to benefit from more intensive interventions, ${ }^{28}{ }^{29}$ and low education levels typically correlate with low SES in China. Our study results are consistent with this conclusion. Smokers with low levels of education exhibit poor levels of health knowledge and weak comprehension skills, and thus they require more frequent and intensive psychological support. The well-educated smoker group included a larger proportion of middle-aged and currently employed individuals with higher family incomes. In China's alcohol-consuming and tobacco-consuming culture, these smokers are more privileged and enjoy access to more forms of social entertainment that involve drinking and smoking in groups. These individuals also experience more work stress, which is relieved through drinking and smoking; thus, these individuals find it more difficult to quit. These individuals quit shortly after the first SCC visit, and the additional follow-up telephone sessions played a limited role.

This study showed that being married and lower levels of nicotine dependence were also significant predictors; these findings complement those of other recent studies. ${ }^{13} 163031$ Smoking behaviours were found to be strongly related to social conventions and customs. Married smokers receive more support from family members, and thus they are more likely to quit. They experience fewer withdrawal symptoms as smokers with lower levels of nicotine dependence can quit easily after receiving smoking intervention services.

We did not detect other predictors of cessation found in previous reports (eg, older age, cessation action stage, occupation, lower cigarette consumption, and lower exhaled CO levels at the time of the first visit ${ }^{16} 172430-33$ ). However, this may be attributable in part to differences in 
population characteristics and intervention methods, and thus a larger sample size is required when detecting more predictors in the future.

Our study presents several limitations. First, regarding our participant recruitment approach, smokers visiting the clinic were not assigned randomly. We did not perform a sample size calculation as quit rates are unpredictable. However, no statistically significant variations in demographic characteristics or tobacco consumption levels were found between the two groups. Although we adjusted for major confounding factors, undetected biases may have affected the results. Second, since approximately $65 \%$ of the smokers resided outside of Beijing, it was not convenient for them to return to our clinic for follow-up sessions and interviews. Only 49 smokers $(9.0 \%)$ returned to the clinic and performed the biochemically validated test. Two of the 49 selfreported non-smokers showed carbon monoxide levels of more than $8 \mathrm{ppm}$, indicating that they had smoked $(4.1 \%)$. Third, the smokers were volunteers and may have been more motivated to quit or less confident in their capacities to quit without professional help. Finally, although the counsellors were unaware of the study objectives, socially desirable responses (observer bias) may have been given.

In conclusion, this study shows that education levels may affect the benefits of repeated counselling sessions on smoking cessation directed at Chinese smokers. Smokers with low levels of education exhibited poor levels of health knowledge and weak levels of comprehension, and thus they were more likely to benefit from the telephone follow-up sessions. Such individuals must be offered more frequent and intensive psychological support than well-educated smokers. Thus, healthcare providers must employ both intervention methods while considering smoker education levels when identifying effective ways to help individuals quit smoking.

\author{
Author affiliations \\ ${ }^{1}$ Department of Epidemiology, Institute of Geriatrics, Chinese People's \\ Liberation Army General Hospital, Beijing, China \\ ${ }^{2}$ Beijing Key Laboratory of Aging and Geriatrics, Chinese People's Liberation \\ Army General Hospital, Beijing, China \\ ${ }^{3}$ State Key Laboratory of Kidney Disease, Chinese People's Liberation Army \\ General Hospital, Beijing, China \\ ${ }^{4}$ Department of Acupuncture, Chinese People's Liberation Army General \\ Hospital, Beijing, China \\ ${ }^{5}$ Department of Respiration, Chinese People's Liberation Army Genera \\ Hospital, Beijing, China \\ ${ }^{6}$ Department of Rehabilitation, Chinese People's Liberation Army General \\ Hospital, Beijing, China
}

Acknowledgements The authors thank Li Xiao, Jinghong Zhu and Jing Feng for their research assistance with the follow-up interview; Tai-hing Lam and Sophia S. C. Chan contributed to the establishment of the clinic and design of the interventions and provided training.

Contributors LW, YH and BJ designed the study and analysed the data. BJ, $\mathrm{FZ}, \mathrm{QL}, \mathrm{CZ}, \mathrm{LZ}, \mathrm{ML}$ and $\mathrm{HC}$ helped in the data collection and field operations. LW wrote the manuscript.

Funding This study was supported by research grants from the National Natural Science Foundation of China, 81373080; Beijing Municipal Science and Technology Commission, Z121107001012070; Clinical Research Grants of Chinese PLA General Hospital, 2013FC-TSYS-1021, MJ201447.

Competing interests None declared.

Patient consent Obtained.

Ethics approval The study was approved by the Independent Ethics Committee of the Chinese People's Liberation Army General Hospital (S2013-066-01).

Provenance and peer review Not commissioned; externally peer reviewed.

Data sharing statement Additional data on the quality appraisal of the included studies are available by emailing wlyg0118@163.com.

Open Access This is an Open Access article distributed in accordance with the Creative Commons Attribution Non Commercial (CC BY-NC 4.0) license, which permits others to distribute, remix, adapt, build upon this work noncommercially, and license their derivative works on different terms, provided the original work is properly cited and the use is non-commercial. See: http:// creativecommons.org/licenses/by-nc/4.0/

\section{REFERENCES}

1. World Health Organization. China wrestles with tobacco control. An interview with Dr Yang Gonghuan. 2010. http://www.who.int/bulletin/ volumes/88/4/10-040410/en/index.htm

2. Yang GH, Li Q, Wang CX, et al. Findings from 2010 Global Adult Tobacco Survey: implementation of MPOWER policy in China. Biomed Environ Sci 2010;23:422-9.

3. Wang C, Cho B, Xiao D, et al. Effectiveness and safety of varenicline as an aid to smoking cessation: results of an inter-Asian observational study in real-world clinical practice. Int $J$ Clin Pract 2013;67:469-76.

4. Levy DT, Romano E, Mumford E. The relationship of smoking cessation to sociodemographic characteristics, smoking intensity, and tobacco control policies. Nicotine Tob Res 2005;7:387-96.

5. De Walque D. Dose education affect smoking behaviors? Evidence using the Vietnam draft as an instrument for college education. $J$ Health Econ 2007;26:877-95.

6. Reid JL, Hammond D, Boudreau C, et al. ITC Collaboration: Socioeconomic disparities in quit intentions, quit attempts, and smoking abstinence among smokers in four western countries: findings from the International Tobacco Control Four Country Survey. Nicotine Tob Res 2010;12(Suppl):S20-23.

7. Ranney L, Melvin C, Lux L, et al. Systematic review: smoking cessation intervention strategies for adults and adults in special populations. Ann Intern Med 2006;145:845-56.

8. Rigotti NA, Munafò MR, Murphy MF, et al. Interventions for smoking cessation in hospitalised patients. Cochrane Database Syst Rev 2003;(1):CD001837.

9. Stead LF, Perera R, Lancaster T. Telephone counselling for smoking cessation. Cochrane Database Syst Rev 2006;(3):CD002850.

10. Hughes JR, Stead LF, Hartmann-Boyce J. Antidepressants for smoking cessation. Cochrane Database Syst Rev 2007;1: CD000031.

11. Stewart DW, Adams CE, Cano MA, et al. Associations between health literacy and established predictors of smoking cessation. Am J Public Health 2013;103:e43-9.

12. Hiscock R, Judge $K$, Bauld L. Social inequalities in quitting smoking: what factors mediate the relationship between socioeconomic position and smoking cessation? J Public Health (Oxf) 2011;33:39-47.

13. Stolz D, Scherr A, Seiffert B, et al. Predictors of success for smoking cessation at the workplace: a longitudinal study. Respiration 2014;87:18-25.

14. Azevedo RC, Fernandes RF. Factors relating to failure to quit smoking: a prospective cohort study. Sao Paulo Med J 2011;129:380-6.

15. Monsó E, Campbell J, Tønnesen P, et al. Sociodemographic predictors of success in smoking intervention. Tob Control 2001;10:165-9.

16. Wenig JR, Erfurt L, Kröger CB, et al. Smoking cessation in groups-who benefits in the long term? Health Educ Res 2013;28:869-78.

17. Zhu WH, Yang L, Jiang CQ, et al. Characteristics of smokers and predictors of quitting in a smoking cessation clinic in Guangzhou, China. J Public Health (Oxf) 2010;32:267-76. 
18. Zheng $\mathrm{P}$, Guo $\mathrm{F}$, Chen $\mathrm{Y}$, et al. A randomized controlled trial of group intervention based on social cognitive theory for smoking cessation in China. J Epidemiol 2007;17:147-55.

19. Abdullah AS, Hedley AJ, Chan SS, et al. Hong Kong council on smoking and health Smoking Cessation Health Centre (SCHC) steering group. Establishment and evaluation of a smoking cessation clinic in Hong Kong: a model for the future service provider. J Public Health (Oxf) 2004;26:239-44.

20. Yang G, Ma J, Chen A, et al. Smoking cessation in China: findings from the 1996 national prevalence survey. Tob Control 2001;10:170-4.

21. Prochaska JO, Goldstein MG. Process of smoking cessation. Implications for clinicians. Clin Chest Med 1991;12:727-35.

22. [No authors listed]. A clinical practice guideline for treating tobacco use and dependence: a US Public Health Service report. The tobacco use and dependence clinical practice guideline panel, staff, and consortium representatives. JAMA 2000;283:3244-54.

23. Lam TH, Abdullah AS, Chan SS, et al., Hong Kong Council on Smoking and Health Smoking Cessation Health Centre (SCHC) Steering Group. Adherence to nicotine replacement therapy versus quitting smoking among Chinese smokers: a preliminary investigation. Psychopharmacology (Berl) 2005;177:400-8.

24. Metz K, Flöter S, Kröger C, et al. Telephone booster sessions for optimizing smoking cessation for patients in rehabilitation centers. Nicotine Tob Res 2007;9:853-63.

25. Raherison C, Marjary A, Valpromy B, et al. Evaluation of smoking cessation success in adults. Respir Med 2005;99:1303-10.
26. Rabius V, Pike KJ, Hunter J, et al. Effects of frequency and duration in telephone counselling for smoking cessation. Tob Control 2007;16 (Suppl 1):i71-4.

27. Zhu SH, Stretch V, Balabanis M, et al. Telephone counselling for smoking cessation: effects of single-session and multiple-session interventions. J Consult Clin Psychol 1996;64:202-11.

28. Siahpush M, McNeill A, Borland R, et al. Socioeconomic variations in nicotine dependence, self-efficacy, and intention to quit across four countries: findings from the International Tobacco Control (ITC) Four Country Survey. Tob Contro. 2006;15(Suppl 3): iii71-5.

29. Berndt N, Bolman C, Froelicher ES, et al. Effectiveness of a telephone delivered and a face-to-face delivered counselling intervention for smoking cessation in patients with coronary heart disease: a 6-month follow-up. J Behav Med 2014;37:709-24.

30. Bhang SY, Choi SW, Ahn JH, et al. Predictors of success at six-month follow-up at a public smoking cessation clinic in South Korea. Asia Pac Psychiatry 2013;5:197-204.

31. Carreras Castellet JM, Maldonado Aróstegui B, Quesada Laborda $\mathrm{M}$, et al. Telephone-based smoking cessation, predictors of success. Med Clin (Barc) 2012;138:242-5.

32. Osler M, Prescott E. Psychosocial, behavioural, and health determinants of successful smoking cessation: a longitudinal study of Danish adults. Tob Control 1998;7:262-7.

33. Steinberg MB, Foulds J, Richardson DL, et al. Pharmacotherapy and smoking cessation at a tobacco dependence clinic. Prevent Med 2006;42:114-19. 